\title{
III Racial/Ethnic Differences in Primary Care Experiences in Patient-Centered Medical Homes among Veterans with Mental Health and Substance Use Disorders
}

\author{
Audrey L. Jones, Ph.D",2, Maria K. Mor, Ph.D ${ }^{1,3}$, John P. Cashy, Ph.D”, \\ Adam J. Gordon, M.D., M.P.H. ${ }^{1,4}$, Gretchen L. Haas, Ph.D ${ }^{5,6}$, James H. Schaefer Jr, M.P.H. ${ }^{7}$, and \\ Leslie R. M. Hausmann, Ph. D ${ }^{1,4}$
}

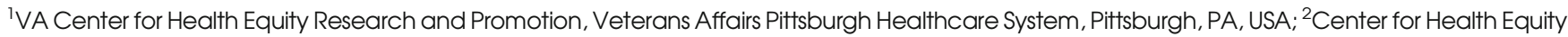
Research and Promotion (CHERP), VA Pittsburgh Healthcare System, Pittsburgh, PA, USA; ${ }^{3}$ Department of Biostatistics, University of Pittsburgh Graduate School of Public Health, Pittsburgh, PA, USA; ${ }^{4}$ Division of General Internal Medicine, Department of Medicine, University of Pittsburgh School of Medicine, Pittsburgh, PA, USA; ${ }^{5}$ VISN4 Mental Illness Research, Education, and Clinical Center, Veterans Affairs Pittsburgh Healthcare System, Pittsburgh, PA, USA; ${ }^{6}$ Department of Psychiatry, University of Pittsburgh School of Medicine, Pittsburgh, PA, USA; ${ }^{7}$ Department of Veterans Affairs Office of Analytics and Business Intelligence, Durham, NC, USA.

BACKGROUND: Patient-Centered Medical Homes (PCMH) may be effective in managing care for racial/ ethnic minorities with mental health and/or substance use disorders (MHSUDs). How such patients experience care in PCMH settings is relatively unknown.

OBJECTIVE: We aimed to examine racial/ethnic differences in experiences with primary care in PCMH settings among Veterans with MHSUDs.

DESIGN: We used multinomial regression methods to estimate racial/ethnic differences in PCMH experiences reported on a 2013 national survey of Veterans Affairs patients.

PARTICPANTS: Veterans with past-year MHSUD diagnoses ( $\mathrm{n}=65,930 ; 67 \%$ White, $20 \%$ Black, $11 \%$ Hispanic, $1 \%$ American Indian/Alaska Native[AI/AN], and $1 \%$ Asian/Pacific Island[A/PI]).

MAIN MEASURES: Positive and negative experiences from the Consumer Assessment of Healthcare Providers and Systems (CAHPS) PCMH Survey.

RESULTS: Veterans with MHSUDs reported the lowest frequency of positive experiences with access (22\%) and the highest frequency of negative experiences with selfmanagement support (30\%) and comprehensiveness (16\%). Racial/ethnic differences (as compared to Whites) were observed in all seven healthcare domains ( $p$ values $<$ 0.05). With access, Blacks and Hispanics reported more negative (Risk Differences [RDs] = 2 .0;3.6) and fewer positive (RDs $=-2$.3;-2.3) experiences, while AI/ANs reported more negative experiences $(\mathrm{RD}=5.7)$. In communication, Blacks reported fewer negative experiences $(\mathrm{RD}=-1.3)$; $\mathrm{AI} / \mathrm{ANs}$ reported more negative $(\mathrm{RD}=3.6)$ experiences; and $\mathrm{AI} / \mathrm{ANs}$ and APIs reported fewer positive $(\mathrm{RD}=-6.5,-6.7)$ experiences. With office staff, Hispanics reported fewer positive experiences $(\mathrm{RDs}=-3.0)$; $\mathrm{AI} / \mathrm{ANs}$ and $\mathrm{A} / \mathrm{PIs}$ reported more negative experiences $(\mathrm{RDs}=3.4 ; 3.7)$. For comprehensiveness, Blacks reported more positive experiences $(\mathrm{RD}=3.6)$, and Hispanics reported more negative experiences $(\mathrm{RD}=2.7)$.

Received January 25, 2016

Revised May 12, 2016

Accepted June 7, 2016

Published online June 20, 2016
Both Blacks and Hispanics reported more positive $(\mathrm{RDs}=$ 2.3 ; 4.2 ) and fewer negative (RDs $=-1.8$; -1.9 ) provider ratings, and more positive experiences with decision making $(\mathrm{RDs}=2.4$; 3.0). Blacks reported more positive $(\mathrm{RD}=3.9)$ and fewer negative $(\mathrm{RD}=-5.1)$ experiences with selfmanagement support.

CONCLUSIONS: In a national sample of Veterans with MHSUDs, potential deficiencies were observed in access, self-management support, and comprehensiveness. Racial/ethnic minorities reported worse experiences than Whites with access, comprehensiveness, communication, and office staff helpfulness/courtesy.

KEY WORDS: patient-centered medical home; health care experience; race and ethnicity; mental health services.

J Gen Intern Med 31(12): 1435-43

DOI: $10.1007 / \mathrm{s} 11606-016-3776-1$

(C) Society of General Internal Medicine 2016

\section{INTRODUCTION}

Approximately $25 \%$ of adults experience a mental health or substance use disorder (MHSUD) each year. ${ }^{1}$ Primary care is often a first step in the treatment of MHSUDs, ${ }^{2,3}$ and this is increasing with new paradigms of primary care, including Patient-Centered Medical Homes (PCMHs). ${ }^{4-6}$ PCMHs use an integrated, team-based approach to delivering primary care services that are comprehensive, patient-centered, accessible, and quality driven. ${ }^{7}$ This model is thought to be particularly helpful in managing care and addressing social determinants of health for vulnerable patients, such as those with MHSUDs. ${ }^{8}$ For example, the PCMH model has been associated with increased visits to mental health specialists, improved adherence to psychiatric medications, and greater mental health recovery for patients with MHSUDs. ${ }^{9-13}$

Despite evidence suggesting that the PCMH model can benefit patients with MHSUDs, a paucity of data exists regarding patient experiences with care in the PCMH. In general, the positive experiences with care reported by outpatient populations have 
been associated with increased health service utilization, adherence to treatment recommendations, and better health outcomes. ${ }^{14,15}$ Patient experiences are particularly important for patients with MHSUDs since negative experiences can contribute to avoidance or discontinuation of mental health treatment. ${ }^{16} \mathrm{We}$ are unaware of any published investigations of MHSUD patient experiences within PCMH settings.

Of additional interest is whether, among patients with MHSUDs, patients of diverse racial/ethnic backgrounds have different experiences with PCMH care. Racial/ethnic minorities are at-risk for poor healthcare experiences in traditional primary care settings, ${ }^{17-27}$ which can contribute to negative physical and mental health outcomes. ${ }^{14}$ In general patient populations, patientreported experiences with accessing healthcare are less positive for Black, Hispanic, and Asian/Pacific Island (A/PI) patients compared to Whites. ${ }^{18,20-25,28,29}$ In the domains of provider communication and office-staff experience, A/PI patients report less positive experiences than Whites, ${ }^{18,22-25,29}$ Black patients report similar or more positive experiences than Whites, and patterns of Hispanic-White differences are mixed. ${ }^{18,20-25,28-30}$ Given that the PCMH model aims to address many of the drivers of racial/ethnic disparities in healthcare (e.g., limited access, fragmentation of services, low satisfaction with care), ${ }^{31}$ it is important to examine whether racial/ethnic differences in healthcare experiences exist within this framework, particularly among those who may already be at risk for poor experiences because of an existing MHSUD. ${ }^{32,33}$ Patient experiences are particularly important for racial/ethnic minorities with MHSUDs who, compared to Whites, are less likely to use mental health/substance abuse services, ${ }^{34}$ and less likely to complete mental health/ substance abuse treatment. ${ }^{35}$

Thus, we sought to examine racial/ethnic differences in patient experiences in a national sample of White, Black, Hispanic, A/PI, and American Indian/Alaska Native (AI/AN) Veterans with MHSUDs who received primary care in PCMH settings. The Veterans Health Administration (VHA) began PCMH transformations in 2010 and collects data on patient experiences aligned with key PCMH goals, including access, comprehensiveness, patient-centered communication, self-management support, and patient involvement in decision making. ${ }^{36}$ We hypothesized that racial/ethnic minority Veterans with MHSUDs would report worse (i.e., more negative and less positive) PCMH experiences than White Veterans. Because other patient characteristics, such as education, age, and MHSUD diagnoses, vary across racial/ ethnic groups ${ }^{37,38}$ and are associated with patient-reported experiences with care, ${ }^{32,33,39}$ we explored whether racial/ethnic differences in experiences with care persisted after controlling for patient sociodemographic and clinical characteristics.

\section{METHODS}

Design. We conducted a cross-sectional analysis to examine racial/ethnic differences in patient-reported PCMH experiences in a national sample of Veterans diagnosed with MHSUDs receiving primary care in VHA between October 2012 and September 2013 (henceforth referred to as "2013").

Data Sources and Study Sample. We used data from the 2013 PCMH-Survey of Healthcare Experiences of Patients (PCMHSHEP) and administrative data from the VHA Corporate Data Warehouse. The PCMH-SHEP is an ongoing survey of primary care experiences conducted by the VHA Office of Analytics and Business Intelligence. ${ }^{40}$ Veterans are eligible for the PCMHSHEP if they are age 18 or older, received VHA outpatient services in the index month, had a primary care visit with an assigned PCMH provider in the 10 months prior to the index month, and did not participate in the prior year's survey. Each month, a stratified, random sample of eligible Veterans is first mailed a letter explaining the goals of the survey, followed by the survey the next week, and a thank-you/reminder postcard the third week.

We linked patient responses from the 2013 PCMH-SHEP to past-year diagnoses and sociodemographic characteristics drawn from administrative records. Veterans were eligible for the current study if, in the year prior to the survey, they experienced one inpatient visit or two outpatient visit days with an International Classification of Diseases version 9 (ICD-9) diagnosis for common MHSUDs, including depression, post-traumatic stress disorder, other anxiety disorders, bipolar disorder, any psychotic disorder, or alcohol or drug use disorder. ${ }^{41}$ To focus on patients with probable mental health service needs, we ignored disorders where remission was indicated (i.e., depression, bipolar disorder, or schizophrenia in remission). In addition, we excluded patients who reported two or more races, because this group is heterogeneous and their findings would be difficult to interpret. Veterans with missing data on one or more sociodemographic variables were also excluded. The VA Pittsburgh Healthcare System's Institutional Review Board approved this study.

Outcome Variables. We examined patient-reported experiences with care in seven domains measured in the PCMH-SHEP survey, which is based on the Consumer Assessment of Healthcare Providers and Systems (CAHPS) PCMH Survey (version 2.0). ${ }^{42,43}$ See Table 1 for individual items, response options, and internal reliability for each domain. Briefly, the access domain assessed timely appointments and care. The communication domain assessed how well providers communicate with patients. The office staff domain assessed staff helpfulness and courtesy or respect. Comprehensiveness assessed whether providers inquire about mental health, substance use, or emotional concerns. Support for selfmanagement assessed whether providers support patients in taking care of their own health. Medication-shared decision making assessed whether providers discussed medication decisions with patients. Finally, Veterans' 
overall rating of their assigned PCMH provider was assessed using a $0-10$ scale.

For all multi-item domains, composite scores were calculated as the average of non-missing items for each individual. Experience ratings were negatively skewed, with most
Veterans reporting positive experiences. We therefore categorized experiences in each domain as negative, moderate, or positive (Table 1). As in prior research, we selected negative and positive cut-points to ensure a sufficient number of participants were included in each category, and to minimize

Table 1. Description of Patient-Centered Medical Home Survey Domains

\begin{tabular}{|c|c|c|c|c|c|}
\hline Domain* Content & $\begin{array}{l}\text { Answer } \\
\text { Choices }\end{array}$ & Reliability $\dagger$ & $\begin{array}{l}\text { Negative } \\
\text { Range }\end{array}$ & $\begin{array}{l}\text { Moderate } \\
\text { Range }\end{array}$ & $\begin{array}{l}\text { Positive } \\
\text { Range }\end{array}$ \\
\hline $\begin{array}{l}\text { Access: In the last } 12 \text { months: } \\
\text { When you phoned this provider's office to get an } \\
\text { appointment for care you needed right away, how } \\
\text { often did you get an appointment as soon as you } \\
\text { needed? } \\
\text { When you made an appointment for a check-up or } \\
\text { routine care with this provider, how often did you } \\
\text { get an appointment as soon as you needed? } \\
\text { How often were you able to get the care you needed } \\
\text { from this provider's office during evenings, } \\
\text { weekends, or holidays? } \\
\text { When you phoned this provider's office during } \\
\text { regular office hours, how often did you get an } \\
\text { answer to your medical question that same day? } \\
\text { When you phoned this provider's office after regular } \\
\text { office hours, how often did you get an answer to } \\
\text { your medical question as soon as you needed? } \\
\text { How often did you see this provider within } \\
15 \text { minutes of your appointment time? }\end{array}$ & $\begin{array}{l}\text { Never (1) } \\
\text { Sometimes (2) } \\
\text { Usually (3) } \\
\text { Always (4) }\end{array}$ & 0.88 & $1.00-1.99$ & $2.00-3.74$ & $3.75-4.00$ \\
\hline $\begin{array}{l}\text { Communication: In the last } 12 \text { months, how often } \\
\text { did this provider: } \\
\text { Explain things in a way that was easy to } \\
\text { understand? } \\
\text { Listen carefully to you? } \\
\text { Give you easy to understand information about the } \\
\text { health questions or concerns? } \\
\text { Seem to known the important information about } \\
\text { your medical history? } \\
\text { Show respect for what you had to say? } \\
\text { Spend enough time with you? }\end{array}$ & $\begin{array}{l}\text { Never (1) } \\
\text { Sometimes (2) } \\
\text { Usually (3) } \\
\text { Always (4) }\end{array}$ & 0.95 & $1.00-2.49$ & $2.50-3.82$ & $3.83-4.00$ \\
\hline $\begin{array}{l}\text { Office Staff: In the last } 12 \text { months, how often: } \\
\text { Were clerks and receptionists at this provider's } \\
\text { office as helpful as you thought they should be? } \\
\text { Did clerks and receptionists at this provider's } \\
\text { office treat you with courtesy and respect? }\end{array}$ & $\begin{array}{l}\text { Never (1) } \\
\text { Sometimes (2) } \\
\text { Usually (3) } \\
\text { Always (4) }\end{array}$ & 0.85 & $1.00-2.49$ & $2.50-3.99$ & 4.00 \\
\hline $\begin{array}{l}\text { Provider Rating: Using any number from } 0 \text { to } 10 \text {, } \\
\text { where } 0 \text { is the worst provider possible and } 10 \text { is } \\
\text { the best provider possible, what number would } \\
\text { you use to rate this provider? }\end{array}$ & $0-10$ & N/A & $0-4$ & $5-9$ & 10 \\
\hline $\begin{array}{l}\text { Comprehensiveness: In the last } 12 \text { months, did anyone } \\
\text { in this provider's office: } \\
\text { Ask you if there was a period of time when you felt } \\
\text { sad, empty, or depressed? } \\
\text { Talk about things in your life that worry you or } \\
\text { cause you stress? } \\
\text { Talk about a personal problem, family problem, } \\
\text { alcohol use, drug use, or a mental or emotional } \\
\text { illness? }\end{array}$ & $\begin{array}{l}\text { Yes (1) } \\
\text { No (0) }\end{array}$ & 0.79 & 0 & $0.01-0.99$ & 1.0 \\
\hline $\begin{array}{l}\text { Medication Decision Making: When you talked about } \\
\text { starting or stopping a prescription medicine: } \\
\text { How much did this provider talk about the reasons } \\
\text { you might want to take the medicine? } \\
\text { How much did this provider talk about the reasons } \\
\text { you might not want to take a medicine? } \\
\text { Did this provider ask you what you thought was } \\
\text { best for you? }\end{array}$ & $\begin{array}{l}\text { Not at all (1) } \\
\text { A little (2) } \\
\text { Some (3) } \\
\text { A lot (4) } \\
\text { Yes (4) } \\
\text { No (1) }\end{array}$ & 0.73 & $1.00-2.00$ & $2.01-3.67$ & $3.68-4.00$ \\
\hline $\begin{array}{l}\text { Self-Management Support: In the last } 12 \text { months, did } \\
\text { anyone in this provider's office: } \\
\text { Talk with you about specific goals for your health? } \\
\text { Ask you if there are things that make it hard for you } \\
\text { to take care of your health? }\end{array}$ & $\begin{array}{l}\text { Yes (1) } \\
\text { No (0) }\end{array}$ & 0.67 & 0 & $0.01-0.99$ & 1.00 \\
\hline
\end{tabular}

* Domains were drawn from the Veterans Healthcare Administration (VHA)'s 2013 Patient-Centered Medical Home Survey of Healthcare Experiences of Patients. Participants include 65,930 VHA outpatients with past year mental health or substance abuse disorder diagnoses

† Chronbach's alpha reported for domains with Likert responses, Kuder-Richardson coefficient reported for domains with dichotomous responses

N/A Reliability not applicable as the domain includes only one item 
potential problems of extreme response tendencies for racial/ ethnic minorities. ${ }^{21,44,45}$

Independent Variables. PCMH-SHEP asks participants to select one or more races (White, Black or African American, Asian, Native Hawaiian or Pacific Islander, American Indian or Alaska Native), and to mark if they are of Hispanic or Latino origin (yes/no). Those who reported Hispanic ethnicity were coded as Hispanic, and those who did not select Hispanic ethnicity were classified according to their self-reported race: White, Black, A/PI, AI/AN, or multiple races. For this analysis, those with multiple races or missing race/ethnicity were excluded due to the difficulty of interpreting results for these groups.

Covariates. We included control variables known to be associated with patient experiences with care. ${ }^{21,39}$ Specifically, age, gender, and marital status were drawn from the administrative record closest to the PCMH-SHEP survey date. Self-reported education, general health ratings and mental health ratings (i.e., In general, would you rate your overall health/mental or emotional health: excellent, very good, good, fair, poor?") were assessed on the PCMH-SHEP. Charlson Comorbidity Index scores were calculated using data from administrative records in the 12 months prior to their PCMHSHEP index month. ${ }^{46}$ We controlled for specific MHSUD diagnoses (e.g., bipolar disorder, psychotic disorder) that vary across racial/ethnic minority groups ${ }^{47-49}$ and may affect patient experiences with care. To account for geographic variations in patient experiences, we controlled for receipt of care at a VHA facility outside the U.S. (i.e., Puerto Rico, Virgin Islands, American Samoa, Philippines), and urban versus rural U.S. residence. We also controlled for insurance (Medicaid, Medicare, private insurance) as a proxy for non-VHA service use.

Statistical Analyses. Analyses were conducted using Stata 13.0. ${ }^{50}$ We applied PCMH-SHEP survey weights to account for participant selection and survey non-response. Standard errors were estimated using a Taylor series approximation that accounted for the stratified sampling design. We used RaoScott chi-square tests to examine overall and pairwise racial/ ethnic minority versus White differences in sociodemographic characteristics and study outcome variables. Multivariable multinomial regression models were employed to estimate racial/ethnic differences in reporting negative, moderate, or positive experiences, adjusting for the measured sociodemographic and clinical characteristics. We converted the multinomial regression coefficients to risk differences to aid in the interpretation of results. That is, we estimated the difference in probability of reporting a positive or negative experience for each racial/ethnic group compared to Whites.

In preliminary analyses we used mixed effect regression methods to explore the need to account for the clustering of racial/ethnic minorities within VHA facilities. The intraclass correlation coefficient for all outcomes was less than $10 \%$, indicating that facility-level variation accounted for only a small percentage of variance in PCMH ratings. Moreover, adjusting for facility characteristics (e.g., patient-mix, facility size) did not meaningfully alter our estimates of racial/ethnic differences. Therefore, the simpler multinomial regression results are presented.

\section{RESULTS}

Of the 598,607 Veteran outpatients included in the sampling time frame, 269,917 (45 \%) completed the PCMH-SHEP survey. Of the survey completers, 72,217 (27\%) had an active past-year MHSUD diagnosis and 65,930 (24\%) met all eligibility criteria (Fig. 1). The final weighted sample was $67 \%$ White, $20 \%$ Black, $11 \%$ Hispanic, $1 \% \mathrm{AI} / \mathrm{AN}$, and $1 \% \mathrm{~A} / \mathrm{PI}$.

Racial/Ethnic Differences in Sociodemographic and Clinical Characteristics among VHA Outpatients with MHSUD Diagnoses. Statistically significant racial/ethnic differences were observed on most sociodemographic and clinical variables (Table 2). Specifically, compared to Whites, Black, Hispanic, $\mathrm{AI} / \mathrm{AN}$, and $\mathrm{A} / \mathrm{PI}$ patients were younger, and Black Veterans were more likely to be female. Hispanics and Blacks rated their general health and mental health as "fair" or "poor" more often than Whites. Blacks and A/PIs more often lived in urban U.S. areas, while Hispanics and A/PIs more often received care at a facility outside the U.S. A/PI patients reported significantly higher educational attainment than Whites.

Hispanic and A/PI patients had lower Charlson comorbidity scores than Whites. Regarding specific MHSUD diagnoses, Hispanics, AI/ANs, and A/PIs had higher rates of posttraumatic stress disorder; Blacks, Hispanics, and A/PIs had lower rates of anxiety disorders and bipolar disorder, but significantly higher rates of psychotic disorders; Blacks had higher rates of alcohol use disorder; and Blacks and APIs had higher rates of drug use disorders.

PCMH Experiences Overall. The proportion of Veterans with positive care experiences ranged from 22 to $60 \%$ across domains, with the fewest positive experiences observed in access (22\%, Table 3). The proportion of Veterans with MHSUDs reporting negative care experiences ranged from 8 to $30 \%$ across domains, with the most negative experiences observed in self-management support. In addition, $16 \%$ of Veterans with MHSUDs reported that their provider did not inquire about mental health concerns, resulting in negative experiences with comprehensiveness.

Racial/Ethnic Differences in PCMH Experiences. Overall tests of racial/ethnic differences revealed significant variations in patient experiences in all domains except provider ratings (Table 3). Adjusted racial/ethnic differences are presented in Figure 2, with Whites serving as the reference group for all comparisons. The patterns of significant adjusted racial/ethnic differences were unique for each domain, as described below. 


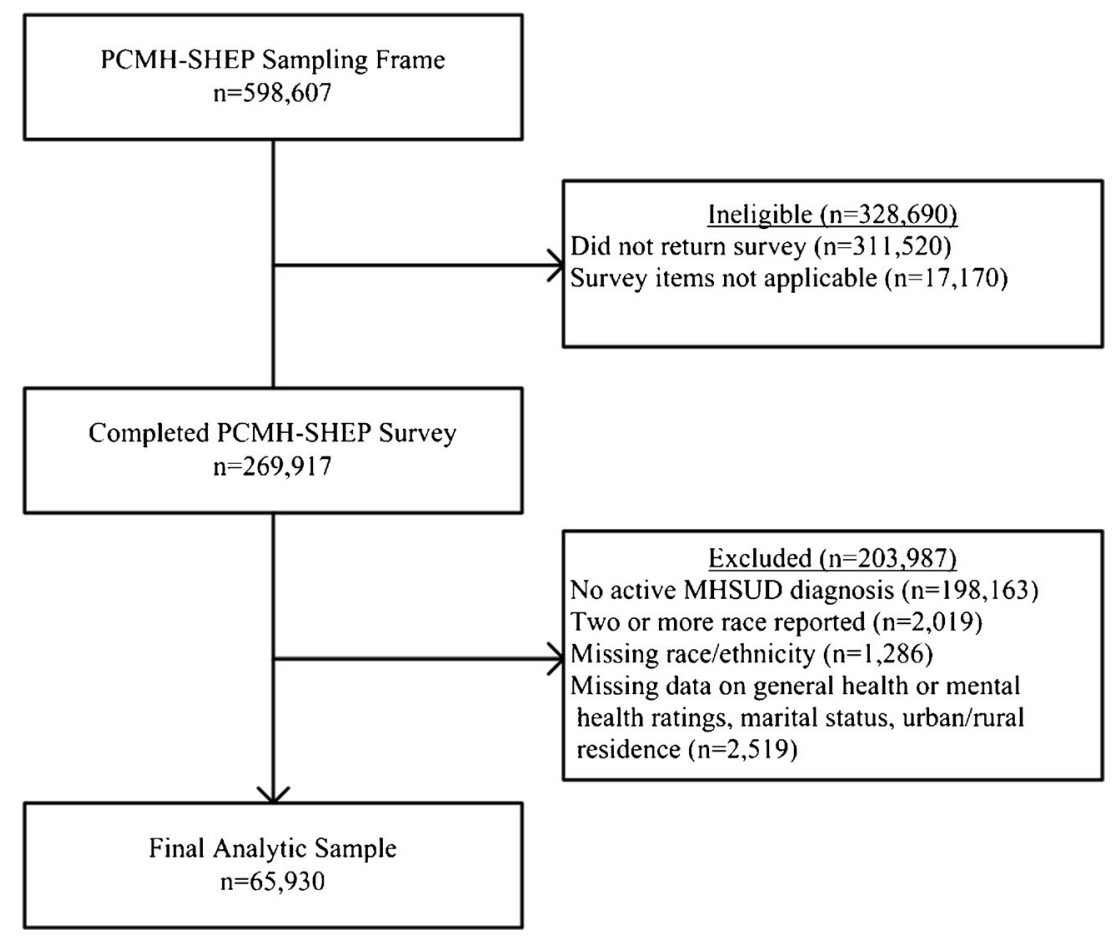

Figure 1. Inclusion and exclusion criteria applied to create an analytic sample of Veterans who completed the 2013 Veterans Healthcare Administration Patient Centered Medical Home Survey of Healthcare Experiences of Patients (PCMH-SHEP) and had an active mental health or substance abuse disorder in the prior year. Exclusion criteria were applied sequentially.

Access. Blacks and Hispanics reported more negative and fewer positive experiences than Whites. AI/ANs also reported more negative experiences, while no significant differences for A/PIs were observed.

Communication. Blacks reported fewer negative experiences with communication than Whites, and no significant differences were found for Hispanics. However, AI/ANs reported more negative and fewer positive experiences and A/PIs reported fewer positive experiences.

Office Staff. No significant differences were observed for Blacks. Alternatively, Hispanics reported fewer positive experiences than Whites, and $\mathrm{AI} / \mathrm{ANs}$ and $\mathrm{A} / \mathrm{PIs}$ reported more negative experiences.

Provider Ratings. Blacks and Hispanics reported more positive and fewer negative ratings, but no significant differences were found for $\mathrm{AI} / \mathrm{ANs}$ or $\mathrm{A} / \mathrm{PIs}$.

Comprehensiveness. Blacks reported more positive experiences, while Hispanics reported more negative experiences. No significant differences for AI/ANs or APIs were observed.

Medication Decision Making. Blacks reported fewer negative experiences, and both Blacks and Hispanics reported more positive experiences. No significant differences were found for $\mathrm{AI} / \mathrm{ANs}$ or $\mathrm{A} / \mathrm{PIs}$.
Self-Management Support. Blacks reported more positive and fewer negative experiences than Whites, but no significant differences existed for Hispanics, AI/ANs, or A/PIs.

\section{DISCUSSION}

This study provides new insights into patient experiences with care within PCMHs for racial/ethnic minority Veterans with MHSUDs. Regardless of race, we identified possible gaps in patient experiences with access, self-management support, and comprehensiveness among Veterans with MHSUDs. In addition, we identified adjusted racial/ethnic differences in experiences with care, with one or more racial/ethnic groups reporting more negative or fewer positive experiences than Whites in domains of access, comprehensiveness, office staff, and communication.

This study increases our understanding of variations in healthcare experiences in several ways. First, prior studies have compared patient-reported experiences for those with MHSUDs versus those without, ${ }^{32,33,51}$ with less attention to racial/ethnic differences among patients with MHSUDs. ${ }^{39}$ Second, prior studies have often excluded small groups such as $\mathrm{AI} / \mathrm{ANs}$ or combined small groups into a heterogeneous "other" category. Third, our investigation of patient experiences includes domains of care added to the core CAHPS survey in 2011 for their relevance to PCMH goals (i.e., comprehensiveness, medication shared-decision making, and selfmanagement support). ${ }^{52}$ These PCMH domains were not assessed in prior studies using the standard CAHPS. 
Table 2. Sociodemographic Characteristics of Veterans with Past-Year Mental Health and Substance Abuse Diagnoses

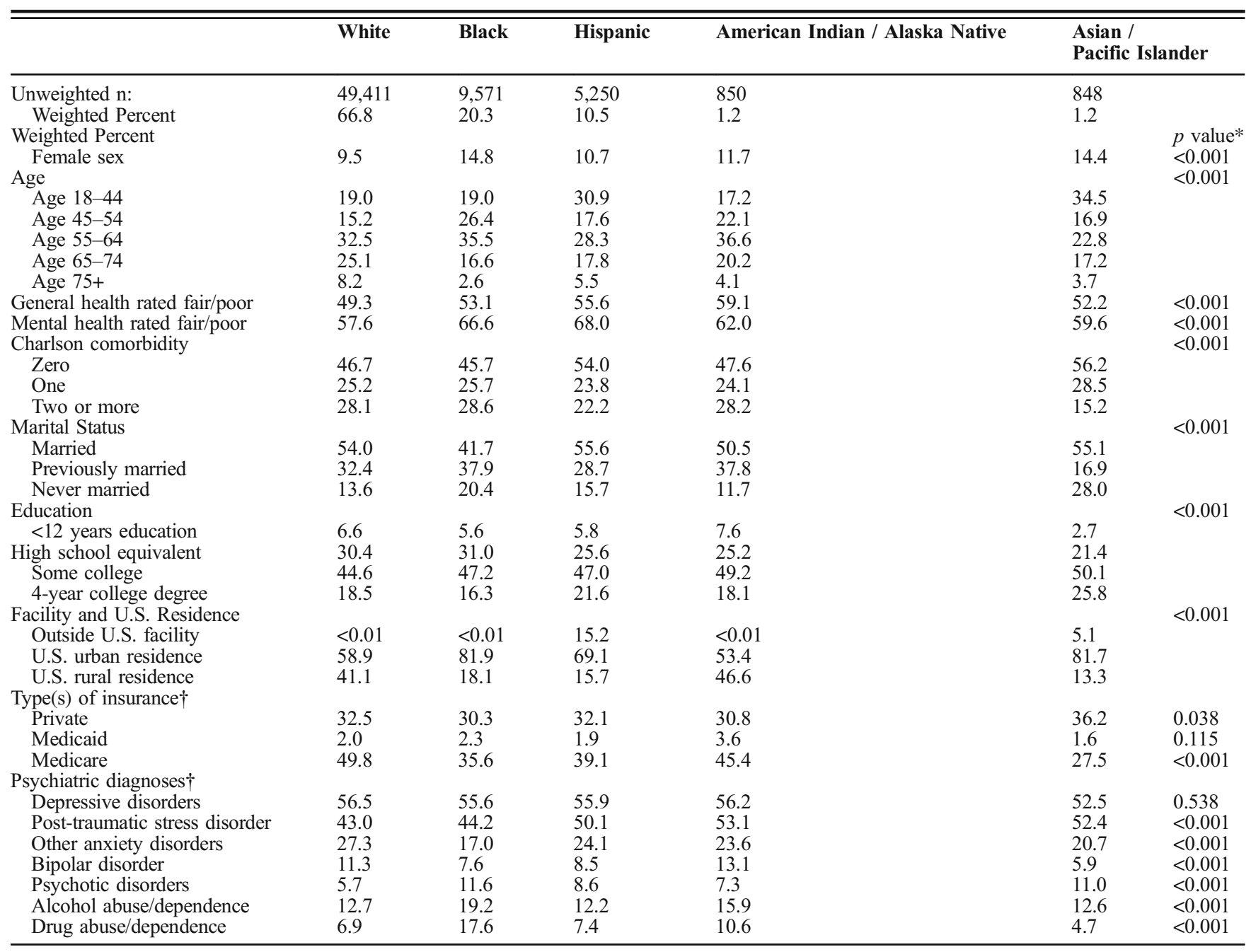

* p value obtained from Rao-Scott chi-square test of differences

+ Categories were not mutually exclusive. Therefore, columns do not add to $100 \%$

Our findings have implications for improving PCMH experiences of Veterans with MHSUDs and for racial/ethnic minority groups, in particular. First, Veterans with MHSUDs regardless of race/ethnicity reported the least positive experiences with access, suggesting that among the dimensions assessed access to care was the most problematic. In addition, in this study, there were consistently less positive and/or more negative patient-reported experiences with access for Blacks, Hispanics, and AI/ANs compared with Whites. Thus, the study findings indicate that special attention needs to be focused on improving access in general, with additional emphasis placed on meeting the access needs of populations with multiple vulnerabilities, including racial/ethnic minorities with MHSUDs.

Second, the relatively high percentage of Veterans reporting negative experiences with self-management support, regardless of racial/ethnic group, suggests this is another area for intervention to improve patient experiences in the PCMH. Patients with MHSUDs experience a disproportionate burden of chronic diseases (e.g., diabetes, hypertension) and are at- risk for premature mortality due to poor management of physical health conditions. ${ }^{53}$ If VHA is using self-management support as a primary or adjunctive modality to address the morbidity of MHSUDs, interventions may be needed to promote more positive experiences. Our finding that Blacks reported more positive experiences with self-management support than did Whites offers a hope that primary care providers may be doing a better job of engaging some racial/ ethnic minorities in self-management strategies.

Third, our finding of racial/ethnic differences in experiences with communication and office staff helpfulness/courtesy indicate that Hispanics, A/PIs, and AI/ANs with MHSUDs may be particularly at-risk for poor interpersonal experiences with care within PCMHs. While these racial/ethnic differences are small $(<5 \%)$, the MHSUD population is vulnerable and atrisk for receiving poor quality care and negative health outcomes. It is possible, then, that even small differences in experiences with communication and office staff may contribute to poor mental health treatment outcomes. ${ }^{16}$ Our results help to lay the groundwork for future research to investigate 
Table 3. Distribution of Negative and Positive Experiences with Care in a Patient-Centered Medical Home by Race/Ethnicity

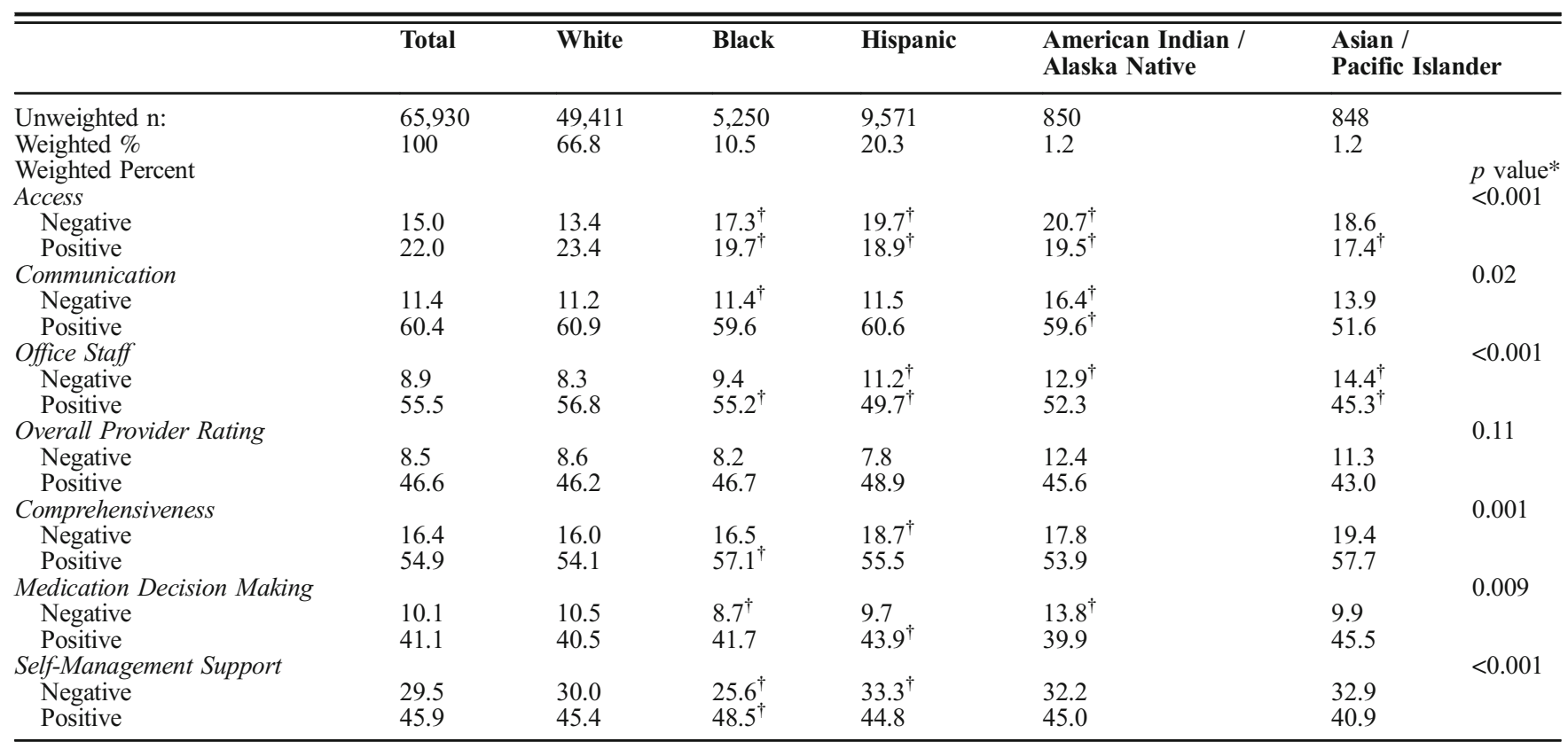

* $p$ value obtained from Rao-Scott chi-square test of differences. For those domains where an overall difference was statistically significant, we conducted pairwise chi-square tests of differences in positive and negative experiences for each racial/ethnic minority group versus Whites.

${ }^{+}$Statistically significantly different from Whites in post-hoc Rao-Scott chi-square tests at $p<0.05$.

how differences in primary care experiences may impact care processes and outcomes for racial/ethnic minority Veterans with MHSUDs.
Study findings also have implications for monitoring racial/ ethnic differences in experiences with care for public reporting or quality improvement purposes. First, our findings suggest

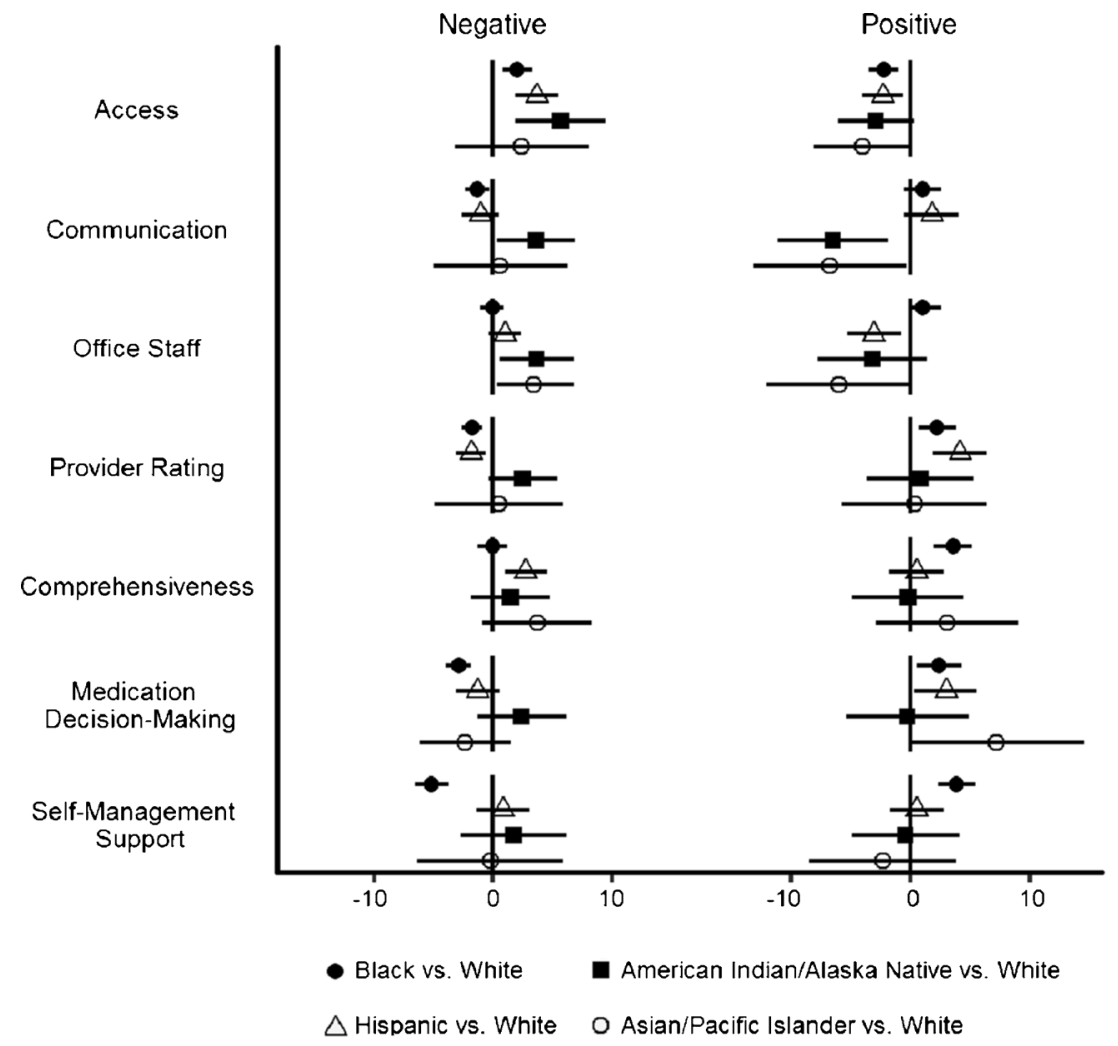

Figure 2. Adjusted racial/ethnic differences in the probability of reporting negative and positive experiences with care. Risk differences were estimated from multivariable multinomial logistic regression models that controlled for age, gender, education, general health and mental health ratings, Charlson comorbidity index scores, marital status, outside U.S. facility, U.S. urban vs. rural residence, insurance, and mental health and substance use disorder diagnoses. 
that focusing exclusively on positive experiences, per existing CAHPS scoring guidelines, ${ }^{52}$ would miss some racial/ethnic differences in negative experiences of care. Negative experiences in comprehensiveness, in particular, warrant evaluation because low scores in this domain indicate no provider inquiry into mental health concerns. Second, the finding of heterogeneous patterns of racial/ethnic differences observed across specific populations underscores the importance of disaggregating racial/ethnic groups when evaluating care in PCMHs. ${ }^{21}$

We acknowledge several study limitations. First, the small numbers of $\mathrm{A} / \mathrm{PI}$ and $\mathrm{AI} / \mathrm{AN}$ Veterans might have reduced our power to detect differences specific to these groups. Second, eligibility for inclusion in our study cohort was defined by ICD-9 diagnoses in the administrative record, thus potentially missing patients with undiagnosed MHSUDs, misclassifying patients with incorrect diagnoses, ${ }^{48}$ and over-including nonsymptomatic patients with a currently documented MHSUD. Third, generalizability of the study findings is limited by several factors. We only examined experiences of Veterans with MHSUD diagnoses receiving primary care services in VHA. Therefore, results may not generalize to civilians, to Veterans receiving primary care in other integrated healthcare systems, or to Veterans without MHSUDs. Moreover, while our survey response rate of $45 \%$ is better than CAHPS PCMH response rates in other outpatient settings, ${ }^{40,41}$ it does limit the generalizability of this study. Fourth, with the data available, we were unable to identify causes of racial/ethnic differences in experiences with care, such as patient expectations or provider biases. Finally, our findings of differences in patient experiences do not necessarily indicate differences in the quality of care received. However, our patient experience measures do capture patient perceptions of care, which are an important factor in treatment adherence and clinical outcomes. ${ }^{16,54}$

\section{CONCLUSIONS}

This study contributes new findings on patient experiences in a diverse national sample of patients with an MHSUD receiving care in VHA's PCMH setting. Study results suggest possible deficits in primary care access, self-management support, and comprehensiveness of care provided to patients with MHSUDs. In addition, our results indicate that ongoing program evaluation and performance improvement processes related to PCMH reforms need to focus more directly on the needs and experiences of racial/ethnic minority populations in order to eliminate racial/ethnic disparities in the domains of access, comprehensiveness, communication, and office staff courtesy/helpfulness. Assumptions that the PCMH framework will uniformly improve patient experiences, and also reduce racial/ ethnic disparities, need to be carefully examined and explicitly tested going forward in the movement to enhance access and quality of care through integration of mental health and primary care services.

Acknowledgements: Dr. Jones is supported as a VA Office of Academic Affiliations Associated Health Professions Post-doctoral Fellow in Health Services Research at the Center for Health Equity Research and Promotion (CHERP) at the VA Pittsburgh Healthcare System. The work reported here was supported by the Department of Veterans Affairs VISN4 CHERP Competitive Research Pilot Program (LIP 72-081). The contents of this article do not represent the views of the Department of Veterans Affairs or the United States Government.

Corresponding Author: Audrey L. Jones, Ph.D; Center for Health Equity Research and Promotion (CHERP)VA Pittsburgh Healthcare System, University Drive (151C), Building 30, Pittsburgh, PA 152401001, USA (e-mail: Audrey.Jones3@va.gov). Compliance with ethical standards:

Conflict of Interest: The authors declare that they do not have a conflict of interest.

\section{REFERENCES}

1. Kessler RC, Chiu WT, Demler O, Merikangas KR, Walters EE. Prevalence, severity, and comorbidity of 12-month DSM-IV disorders in the National Comorbidity Survey Replication. Arch Gen Psychiatry. 2005;62:617-627.

2. Szymanski BR, Bohnert KM, Zivin K, McCarthy JF. Integrated care: treatment initiation following positive depression screens. J Gen Intern Med. 2013;28:346-352.

3. Petterson S, Miller BF, Payne-Murphy JC, Phillips RL. Mental health treatment in the primary care setting: Patterns and pathways. Fam Syst Health. 2014;32:157-166.

4. Baird M, Blount A, Brungardt S, et al. Joint principles: integrating behavioral health care into the patient-centered medical home. Ann Fam Med. 2014;12:183-185.

5. Bao Y, Casalino LP, Pincus HA. Behavioral health and health care reform models: patient-centered medical home, health home, and accountable care organization. J Behav Health Serv Res. 2013;40:121-132.

6. Edwards ST, Bitton A, Hong J, Landon BE. Patient-centered medical home initiatives expanded in 2009-13: providers, patients, and payment incentives increased. Health Aff. 2014;33:1823-1831.

7. Patient centered medical home resource center: defining the PCMH. [AHRQ web site]. Available at: http://pcmh.ahrq.gov/page/defining-pcmh. Accessed June 1, 2016

8. O'Toole TP, Pirraglia PA, Dosa D, et al. Building care systems to improve access for high-risk and vulnerable veteran populations. J Gen Intern Med. 2011;26(Suppl 2):683-688.

9. Domino ME, Wells R, Morrissey JP. Serving persons with severe mental illness in primary care-based medical homes. Psychiatr Serv. 2015;66:477-483.

10. Beadles CA, Farley JF, Ellis AR, et al. Do medical homes increase medication adherence for persons with multiple chronic conditions? Med Care. 2015;53:168-176.

11. Sklar M, Aarons GA, O'Connell M, Davidson L, Groessl EJ. Mental Health Recovery in the Patient-Centered Medical Home. Am J Public Health. 2015; 105:1926-1934.

12. Randall I, Mohr DC, Maynard C. VHA patient-centered medical home associated with lower rate of hospitalizations and specialty care among Veterans with posttraumatic stress disorder. J Healthc Qual. 2015

13. Jones AL, Cochran SD, Leibowitz A, Wells K, Kominski G, Mays VM. Usual primary care provider characteristics of a patient-centered medical home and mental health services use. J Gen Intern Med. 2015;30:18281836.

14. Anhang Price R, Elliott MN, Zaslavsky AM, et al. Examining the role of patient experience surveys in measuring health care quality. Med Care Res Rev. 2014;71:522-554

15. Institute of Medicine Committee on Quality of Health Care in America. Crossing the Quality Chasm: A New Health System for the 21st Century. Washington (DC): National Academies Press; 2001.

16. True G, Rigg KK, Butler A. Understanding Barriers to Mental Health Care for Recent War Veterans Through Photovoice. Qual Health Res. 2015;25:1443-1455. 
17. Ly DP, Glied SA. Disparities in service quality among insured adult patients seen in physicians' offices. J Gen Intern Med. 2010;25:357-362.

18. Borders TF, Lensing S, Xu KT. Health confidence and racial and ethnic disparities in consumers' assessments of health care. Am J Med Gual. 2011;26:220-228.

19. Campbell JL, Ramsay J, Green J. Age, gender, socioeconomic, and ethnic differences in patients' assessments of primary health care. Qual Health Care. 2001;10:90-95.

20. Gary TL, Narayan KM, Gregg EW, Beckles GL, Saaddine JB. Racial/ ethnic differences in the healthcare experience (coverage, utilization, and satisfaction) of US adults with diabetes. Ethn Dis. 2003;13:47-54.

21. Hausmann LR, Gao S, Mor MK, Schaefer JH Jr, Fine MJ. Understanding racial and ethnic differences in patient experiences with outpatient health care in Veterans Affairs Medical Centers. Med Care. 2013;51:532-539.

22. Lurie N, Zhan C, Sang1 J, Bierman AS, Sekscenski ES. Variation in racial and ethnic differences in consumer assessments of health care. Am J Manag Care. 2003;9:502-509.

23. Rodriguez HP, von Glahn T, Grembowski DE, Rogers WH, Safran DG. Physician effects on racial and ethnic disparities in patients' experiences of primary care. J Gen Intern Med. 2008;23:1666-1672.

24. Shi L, Macinko J. Changes in medical care experiences of racial and ethnic groups in the United States, 1996-2002. Int J Health Serv. 2008;38:653-670.

25. Taira DA, Safran DG, Seto TB, et al. Do patient assessments of primary care differ by patient ethnicity? Health Serv Res. 2001;36:1059-1071.

26. Weech-Maldonado R, Elliott MN, Adams JL, et al. Do racial/ethnic disparities in quality and patient experience within Medicare plans generalize across measures and racial/ethnic groups? Health Serv Res. 2015;50:1829-1849.

27. Wilkins V, Elliott MN, Richardson A, Lozano P, Mangione-Smith R. The association between care experiences and parent ratings of care for different racial, ethnic, and language groups in a Medicaid population. Health Serv Res. 2011;46:821-839.

28. Shi L, Lebrun-Harris LA, Daly CA, et al. Reducing disparities in access to primary care and patient satisfaction with care: the role of health centers. $J$ Health Care Poor Underserved. 2013;24:56-66.

29. Weech-Maldonado R, Morales LS, Elliott M, Spritzer K, Marshall G, Hays RD. Race/ethnicity, language, and patients' assessments of care in Medicaid managed care. Health Serv Res. 2003;38:789-808.

30. O'Brien M, Shea J. Disparities in patient satisfaction among Hispanics: the role of language preference. J Immigr Minor Health. $2011 ; 13: 408-412$

31. Beal AC, Doty MM, Hernandez SE, Shea KK, Davis K. Closing the Divide: How Medical Homes Promote Equity In Health Care. Results From The Commonwealth Fund 2006 Health Care Quality Survey: The Commonwealth Fund; 2007

32. Desai RA, Stefanovics EA, Rosenheck RA. The role of psychiatric diagnosis in satisfaction with primary care: data from the department of veterans affairs. Med Care. 2005;43:1208-1216.

33. Kilbourne AM, McCarthy JF, Post EP, et al. Access to and satisfaction with care comparing patients with and without serious mental illness. Int $\mathrm{J}$ Psychiatry Med. 2006;36:383-399.

34. Agency for Healthcare Research and Quality (2014) National healthcare quality and disparities report. Rockville, MD: U.S. Department of Health and Human Services; 2015: http://www.ahrq.gov/sites/default/files/wysiwyg/research/findings/nhqrdr/nhqdr14/2014nhqdr.pdf. Accessed June 1,2016

35. Saloner B, Le Cook B. Blacks and Hispanics are less likely than whites to complete addiction treatment, largely due to socioeconomic factors. Health Affairs. 2013;32:135-145.
36. Nelson KM, Helfrich C, Sun $\mathbf{H}$, et al. Implementation of the patientcentered medical home in the Veterans Health Administration: associations with patient satisfaction, quality of care, staff burnout, and hospital and emergency department use. JAMA Intern Med. 2014;174:1350-1358.

37. Chrishon K, Anderson D, Arora G, Bailey TK. Race and psychiatric diagnostic patterns: understanding the influence of hospital characteristics in the National Hospital Discharge Survey. J Natl Med Assoc. 2012;104:505-509.

38. Miranda J, McGuire TG, Williams DR, Wang P. Mental health in the context of health disparities. Am J Psychiatry. 2008;165:1102-1108.

39. Burnett-Zeigler I, Zivin K, Ilgen MA, Islam K, Bohnert AS. Perceptions of quality of health care among veterans with psychiatric disorders. Psychiatr Serv. 2011;62:1054-1059.

40. VHA Office of Analytics and Business Intelligence. The SHEP Patient Centered Medical Home (PCMH) Survey Technical Specifications. Washington DC: Department of Veterans Affairs; 2012: http://vaww.car.rtp. med.va.gov/filedownload.ashx?fid=8346. Accessed June 1, 2016.

41. Frayne SM, Miller DR, Sharkansky EJ, et al. Using administrative data to identify mental illness: what approach is best? Am J Med Qual. 2010;25:42-50.

42. Hays RD, Berman LJ, Kanter MH, et al. Evaluating the psychometric properties of the CAHPS Patient-centered Medical Home survey. Clin Ther. 2014;36:689-696. e681.

43. Scholle SH, Vuong O, Ding $\mathbf{L}$, et al. Development of and field test results for the CAHPS PCMH Survey. Med Care. 2012;50(Suppl):S2-10.

44. Weech-Maldonado R, Elliott MN, Oluwole A, Schiller KC, Hays RD. Survey response style and differential use of CAHPS rating scales by Hispanics. Med Care. 2008;46:963-968.

45. Hausmann LR, Gao S, Mor MK, Schaefer JH Jr, Fine MJ. Patterns of sex and racial/ethnic differences in patient health care experiences in US Veterans Affairs hospitals. Med Care. 2014;52:328-335.

46. Deyo RA, Cherkin DC, Ciol MA. Adapting a clinical comorbidity index for use with ICD-9-CM administrative databases. J Clin Epidemiol. 1992;45:613-619

47. Alegria M, Nakash O, Lapatin S, et al. How missing information in diagnosis can lead to disparities in the clinical encounter. J Public Health Manag Pract. 2008;14(Suppl):S26-35.

48. Blow FC, Zeber JE, McCarthy JF, Valenstein M, Gillon L, Bingham CR. Ethnicity and diagnostic patterns in veterans with psychoses. Soc Psychiatry Psychiatr Epidemiol. 2004;39:841-851.

49. Williams EC, Lapham GT, Hawkins EJ, et al. Variation in documented care for unhealthy alcohol consumption across race/ethnicity in the Department of Veterans Affairs Healthcare System. Alcohol Clin Exper Res. 2012;36:1614-1622.

50. Stata [computer program]. Version 13. College Station, TX: StataCorp LP; 2013.

51. Martino SC, Elliott MN, Haviland AM, Saliba D, Burkhart Q, Kanouse DE. Comparing the health care experiences of Medicare beneficiaries with and without depressive symptoms in Medicare managed care versus fee-forservice. Health Serv Res. 2015

52. CAHPS Patient-Centered Medical Home (PCMH) Item Set [AHRQ web site] Available at: http://www.ahrq.gov/sites/default/files/wysiwyg/cahps/ surveys-guidance/survey4.0-docs/1314_About_PCMH.pdf. Accessed June 3, 2016.

53. Druss BG, Zhao L, Von Esenwein S, Morrato EH, Marcus SC. Understanding excess mortality in persons with mental illness: 17-year follow up of a nationally representative US survey. Med Care. 2011;49:599-604.

54. Kim TW, Samet JH, Cheng DM, Winter MR, Safran DG, Saitz R. Primary care quality and addiction severity: a prospective cohort study. Health Serv Res. 2007;42:755-772. 